Dear author,

Please note that changes made in the online proofing system will be added to the article before publication but are not reflected in this PDF.

We also ask that this file not be used for submitting corrections. 


\title{
Influence of microstructure on fluid transport and mechanical properties in structural concrete produced with lightweight clay aggregates
}

\author{
C. Pla ${ }^{\mathrm{a}, *}$, A.J. Tenza-Abril ${ }^{\mathrm{a}}$, J. Valdes-Abellan $^{\mathrm{a}}$, D. Benavente ${ }^{\mathrm{b}}$ \\ ${ }^{a}$ Department of Civil Engineering, University of Alicante, Alicante, Spain \\ ${ }^{\mathrm{b}}$ Department of Environment and Earth Sciences, University of Alicante, Alicante, Spain
}

\section{H I G H L I G H T S}

- Lightweight aggregates do not affect the fluid transport properties of concrete.

- An increase of lightweight aggregates volume affects the mechanical properties.

- Fluid transport in lightweight concrete is regulated by the mortar matrix properties.

- Lightweight particles are isolated by an external denser shell.

\section{A R T I C L E I N F O}

\section{Article history:}

Received 17 August 2017

Received in revised form 15 March 2018

Accepted 19 March 2018

Available online $\mathrm{xxxx}$

\section{Keywords:}

Lightweight concrete

Permeability

Sorptivity

Porous system

Clayed aggregates

\begin{abstract}
A B S T R A C T
The use of lightweight aggregates (LWA) in concrete is an interesting alternative to simultaneously reduce the total structure weight and provide both appropriate resistance and concrete's performance. This paper studies the influence of LWA on concrete, comparing the changes in the mechanical properties, pore structure and fluid transport related to the increase of LWA content. Results reveal that although LWA reduces the mechanical properties of the studied samples does not significantly affect the fluid transport properties. Total porosity rises with LWA content whereas open porosity remains nearly invariable. LWA pores do not totally participate in the fluid transport through the concrete and, consequently, fluid transport through lightweight concrete is limited by the continuity and accessibility of the LWA pores and is dominated by the properties of the mortar matrix.
\end{abstract}

(c) 2018 Published by Elsevier Ltd.

\section{Introduction}

Durability and mechanical resistance are considered key properties in the election of concrete as a construction material. Normally, both durability and mechanical resistance can be enhanced using highly dense concretes. However, this solution implies the use of part of the structure strength to support its own weight. Alternatively, the concrete industry has introduced different materials and additions to improve concrete features and performance with low density concretes.

Among these alternatives, the replacement of normal aggregates by lightweight aggregates (LWA) has proved advantages such as the improvement of thermo-insulation properties and the reduction of concrete density [1]. Nevertheless, LWA are generally

\footnotetext{
* Corresponding author at: Department of Civil Engineering, Universidad of Alicante, Campus San Vicente del Raspeig s/n, 03690 San Vicente del Raspeig, Alicante, Spain.

E-mail addresses: c.pla@ua.es (C. Pla), ajt.abril@ua.es (A.J. Tenza-Abril), javier. valdes@ua.es (J. Valdes-Abellan), david.benavente@ua.es (D. Benavente).
}

more porous than the concrete matrix and durability might be negatively affected. As a consequence, the research focused in lightweight concrete (LWC) has experienced an extensive growth, mainly related to concrete deterioration and fluids migration through the porous system.

The main deterioration processes of concrete are triggered by the movement of fluids or aggressive substances from the environment where the structure is built to inside the structure by capillary absorption, permeability of gases and liquids or diffusion [25]. In particular, capillary absorption predominates when the porous medium is not saturated, while permeability is the principal mechanism when concrete is completely saturated with the fluid. Despite the higher porosity of LWA, an increase of pore connectivity in LWC might not be associated with the increase of LWA in the concrete mixture, as it has been previously observed by [6] or [7]. Moreover, previous studies [8,9] reported that the interaction of the lightweight aggregate and the mortar matrix is related to excellent durability performance in some LWC. Although might be only restricted to some types of LWA, in some cases, chemical 
reactions between the aggregate and the matrix can create an interface surrounding the LWA particles. This interface contributes to slightly improve both, strength [8] and fluids migration resistance, since mechanical properties depend on the aggregate strength and the mortar matrix, as well as the bonding structure of the aggregate/matrix interfacial zone $[10,11]$.

Nowadays, LWC can be produced in a wide range of densities and strengths according to the requirements of the final use [12]. Lightweight expanded clay aggregates are one of the most common LWA employed in the construction industry due to its low production cost and excellent chemical stability and require a special attention from the research community.

In this paper, a comparative study between different lightweight concrete and normal weight concrete has been performed with the aim of determining the changes in the mechanical properties, pore structure and fluid transport with the addition of lightweight expanded clay aggregates. In particular, the influence of LWA and mortar matrix on mechanical and durability properties of concrete is evaluated and the role of microstructure on fluids movement through the samples is determined. An ANOVA analysis is carried out on results in order to identify significant variations of the concrete properties with the increase of LWA. Results from this study show that high-performance concrete can be obtained using lightweight expanded clay aggregates with low densities and no significant impact on durability properties.

\section{Materials and methods}

\subsection{Materials}

The different lightweight concretes (LWC) included coarse and fine limestone aggregates (CLA and FLA, respectively), lightweight aggregates (LWA) from SaintGobain Company (Arlita Leca HS) and cement (CEM I 52.5 SR) with an absolute density of $3176 \mathrm{~kg} / \mathrm{m}^{3}$. The main properties of the aggregates are collected in Table 1.

The aggregate fraction was determined according to standard [13]. For LWA, FLA and CLA, determination of loose bulk density and voids and particle densities was conducted following [14]. Water absorption at $24 \mathrm{~h}$ was performed using pre-dried lightweight particles immersed in water according to [15]. Finally, the water absorption and weight ratio were measured in both total and fractured particles and lasted from 1.5 min up to 28 days (Fig. 1). Fractured particles were measured following a specific methodology based on the standard 933.5 [16]. The fractured particles constitute $3.1 \%$ of LWA fraction.

Four different types of concrete were produced, according to a final target density of 1700,1900 and $2200 \mathrm{~kg} / \mathrm{m}^{3}$ for the LWC (samples LWC-1, LWC-2 and LWC-3 respectively) and an additional normal weight concrete (NWC) fabricated to compare results (with density higher than $2200 \mathrm{~kg} / \mathrm{m}^{3}$ ). All four concrete types had the same $\mathrm{w} / \mathrm{c}$ ratio $(0.6)$, cement content $\left(350 \mathrm{~kg} / \mathrm{m}^{3}\right)$, water $\left(210 \mathrm{~kg} / \mathrm{m}^{3}\right)$ and FLA $\left(750 \mathrm{~kg} / \mathrm{m}^{3}\right)$. Concrete dosage was accomplished by following the Fanjul method [17]. Different amounts of CLA and LWA were used to achieve the required densities (Table 2). Thus, the mortar remained the same for all concretes (water, cement and fine limestone aggregate) and the coarse aggregate was the component that changed among the four concrete types (LWA and CLA).

The $\mathrm{w} / \mathrm{c}$ ratio informs about the effective water available for cement hydration and it is directly related to the concrete workability. Due to the high water absorption capacity of LWA, previous measurement of superficial and internal water content in LWA was required. This measurement implied the submersion of pre-soaked LWA in water during 7 days; after that, LWA were extended in a mesh for 20 min to reduce the superficial water content and placed into hermetic plastic bags to pre-

Table 1

Physical characteristics of the aggregates (Lightweight aggregates, LWA; fine limestone aggregates, FLA; coarse limestone aggregates; CLA).

\begin{tabular}{llll}
\hline Property & LWA & FLA & CLA \\
\hline Granulometric fraction $\left(\mathrm{d}_{\mathrm{i}} / \mathrm{D}_{\mathrm{i}}\right)^{*}$ & $4 / 10$ & $0 / 4$ & $6 / 12$ \\
Loose bulk density $\left(\mathrm{kg} / \mathrm{m}^{3}\right)$ & 610 & 1610 & 1376 \\
Voids $(\%)$ & 38.6 & 40.3 & 48.8 \\
Apparent particle density $\left(\mathrm{kg} / \mathrm{m}^{3}\right)$ & 1221 & 2716 & 2714 \\
Oven dry particle density $\left(\mathrm{kg} / \mathrm{m}^{3}\right)$ & 962 & 2708 & 2669 \\
Saturated surface dry particle density $\left(\mathrm{kg} / \mathrm{m}^{3}\right)$ & 1173 & 2710 & 2685 \\
24 h water absorption $(\%)$ & 16.7 & 0.12 & 0.62 \\
\hline
\end{tabular}

$\mathrm{d}_{\mathrm{i}}$ : minor diameter $(\mathrm{mm})$; $\mathrm{D}_{\mathrm{i}}$ : mayor diameter $(\mathrm{mm})$.

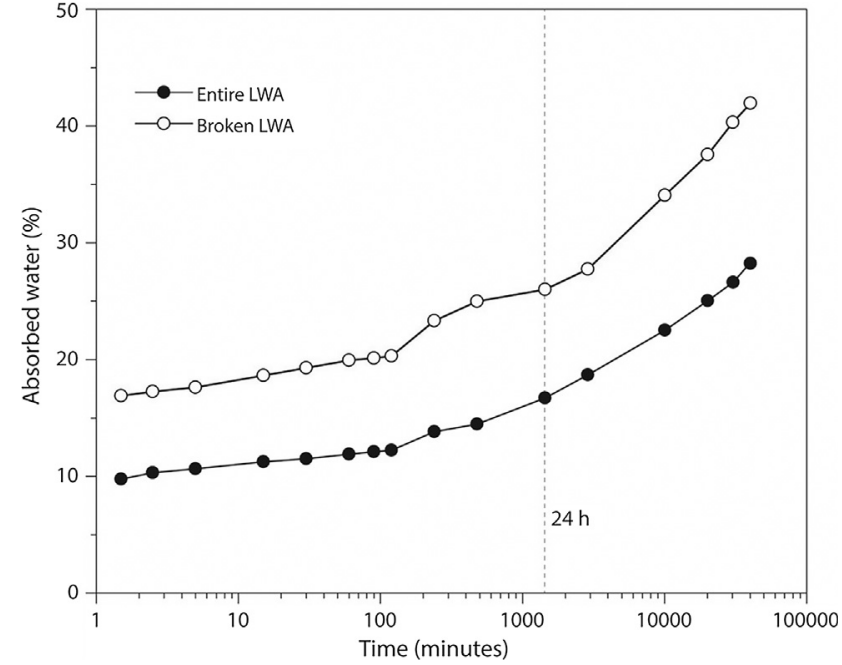

Fig. 1. Water absorption test in LWA (entire and broken particles) according to UNE-EN 1097-6.

Table 2

Mix proportions $\left(\mathrm{kg} / \mathrm{m}^{3}\right)$.

\begin{tabular}{lll}
\hline Code & CLA & LWA \\
\hline LWC-1 & 1 & 389 \\
LWC-2 & 315 & 275 \\
LWC-3 & 787 & 104 \\
NWC & 1042 & - \\
\hline
\end{tabular}

vent water losses before the mixing process. Afterwards, a LWA sample with superficial and internal water was weighed, placed in a sieve covered by a paper filter sheet and vibrated during $15 \mathrm{~s}$ to remove the superficial water content. Later, this LWA sample without superficial water was weighed and oven dried until constant mass to obtain the internal water content. Superficial water content was subtracted from total mixing water to keep constant the $\mathrm{w} / \mathrm{c}$ ratio.

All initial materials were mixed in a vertical shaft mixer. The mixing methodology for all concretes consisted of one-minute mixing cement and fine aggregate, two-minutes mixing after the addition of the total calculated water, two-minutes mixing after the addition of the coarse aggregate. The specimens were demolded after $24 \mathrm{~h}$ and exposed to underwater curing for 28 days.

\subsection{Microstructural analysis}

The microstructural study was mainly based on mercury intrusion porosimetry (MIP) and scanning electron microscopy (SEM). MIP determined the porosity and pore size distribution of the LWA and the mortar matrix, and SEM described the LWC microstructure, including porosity of LWA and mortar, the changes in the interfacial transition zone, the cracks around the coarse limestone aggregates, etc. MIP was measured with an Autopore IV 9500 Micromeritics. The employed surface tension and contact angle of mercury were $480 \mathrm{mN} / \mathrm{m}$ and $130^{\circ}$, respectively.

The concrete specimens were cut in regular samples of approximately $1 \mathrm{~cm}^{3}$ and observed using scanning electron microscopy at voltage of 5-30 keV in lowand high-vacuum modes with a Hitachi S3000N. Uncover samples were employed to develop some visual inspections and EDX (energy dispersive X-ray) was applied to obtain basic chemical analysis of the elements associated with the SEM images. SEM images under high-vacuum mode were captured after EDX analysis, by coating the samples with a thin film of gold.

\subsection{Porosity and density}

For each concrete type, $\emptyset 30 \times 50 \mathrm{~mm}$ samples were extracted from $\emptyset 150 \times 300$ specimens for the porosity and density tests. The ratio between bulk and grain densities determined total porosity. Bulk density was calculated through direct measurement of dried weights and dimensions of samples. The ratio of the mass to the solid volume of a material defines its grain or real density, which was obtained with an AccuPyc 1330 Helium pycnometer. The vacuum water saturation test [18] was employed to obtain the open porosity, i.e., the ratio of the volume of connected voids to the total sample volume. 
The compressive strength test based on [19] was determined in $150 \mathrm{~mm}$ cubic specimens. Prismatic samples $(100 \times 100 \mathrm{~mm}$ side and $400 \mathrm{~mm}$ length $)$ were employed to determine the flexural strength [20] and cylinders $(\varnothing 150 \times 300 \mathrm{~mm})$ were necessary to calculate the static modulus of elasticity according to [21] and using LVDT displacement transducers to measure linear displacement. All tests were developed by triplicate with specimens at the age of 28 days. According to the transmission method, ultrasonic measurements were developed in $\emptyset 150 \times$ $300 \mathrm{~mm}$ samples. The method consists of two piezoelectric sensors coupled to polarised Panametric transducers $(0.25 \mathrm{MHz})$ and a PUNDIT LAB+ non-destructive device. For the tested samples, the obtained ultrasonic wave velocities $\left(V_{P}\right.$ and $V_{S}$ ) and the measured bulk density, $(\rho)$, were employed to calculate the dynamic elastic constants of the concrete. The Poisson ratio, $v$ (Eq. (1)), and Young's modulus, Ed (Eq. (2)), were calculated as follows:

$v=\frac{\left(V_{P}-V_{S}\right)^{2}-2}{2\left(V_{P}-V_{S}\right)^{2}-1}$

$E_{d}=\rho V_{P}^{2} \frac{(1-2 v)(1+v)}{(1-v)}$

The test was performed by triplicate using $\emptyset 150 \times 50 \mathrm{~mm}$ specimens at the age of 28 days. The pre-conditioning of specimens was established according to the standard procedure [22] as follows: after curing, the specimens were oven dried at $50{ }^{\circ} \mathrm{C}$ for 4 days. Then specimens were fit in a sealed recipient in order to avoid moisture exchange. These recipients had similar dimensions to the sample size and they were placed in the oven at $50{ }^{\circ} \mathrm{C}$ for 3 days. Finally, samples were stored in a chamber with $20^{\circ} \mathrm{C}$ and $65 \%$ of relative humidity for 21 days.

Gas permeability coefficients $\left(\mathrm{K}_{\mathrm{g}}\right)$ were determined according to [23] recommendations in a Cembureau type permeameter. The permeability test was carried out using $\mathrm{N}_{2}$ for inlet gas pressures ranging from 50 to $300 \mathrm{kPa}$, depending on the different samples. The Cembureau permeameter consists of a pressure cell for $\emptyset 150 \times 50 \mathrm{~mm}$ samples and calibrated soap bubble flow meters with different volumes. When the gas is introduced in the permeability cell at the selected input pressures, the time taken for the soap bubble to go through the volume defined by the flowmeter is recorded. To select the appropriate volume of the flow meter, the time reading must be higher than $20 \mathrm{~s}$. Measurements were repeated for each sample until achieving successive readings with differences lower than $3 \%$ within a time interval of 5-15 min. This procedure was repeated with increased pressures.

For each specimen, gas permeability coefficients $\left(\mathrm{K}_{\mathrm{g}}\right)$ were obtained using the modified Darcy's equation under steady-state flux conditions following [23] recommendations.

\subsubsection{Capillary water absorption}

Water absorption by capillarity was performed for the different types of concrete according to [24] in three $\varnothing 150 \times 50 \mathrm{~mm}$ oven dried specimens at the age of 28 days. The oven dried temperature was $50{ }^{\circ} \mathrm{C}$ and samples were preconditioned following the same procedure than the described for the gas permeability sample preparation [22]. the sample at constant pressure. Ultrasonic measurements were achieved by

One-dimensional flux in the samples was ensured by coating the vertical sample surfaces. Water absorbed per area of the sample was plotted versus the square root of time to determine the water absorption coefficient by capillarity, C. The capillarity coefficient is related to sorptivity (S), which describes the height variation of water in the sample, by $C=S \cdot \rho_{\mathrm{W}}$, where $\rho_{\mathrm{W}}$ is the water density [25].

\subsubsection{Water retention curve}

Water retention curves were determined in concrete samples of $\emptyset 50 \mathrm{~mm} \times 5$ $\mathrm{mm}$ thick equilibrated in a closed chamber at constant temperature (isothermal equilibrium conditions $25 \pm 1^{\circ} \mathrm{C}$ ) until constant weight [26-28]. The different relative humidities in the closed chambers were obtained by saturated salt solutions, covering a range from $35 \%$ to $95 \%$. The elapsed time to reach equilibrium depended on relative humidity. Relative humidity was transformed into matric potential Pc $\mathrm{Pa}$ ) using the Kelvin-Laplace relationship. Water gain was obtained by weight, later transformed to volumetric water content. Afterwards, the van Genuchten model [29] was adopted and its shape parameters were obtained by fitting the model to experimental data, as described in [27].

\subsubsection{Statistical analysis}

The analysis of variance (ANOVA) was used to ascertain the effects of LWA in the concrete samples and to detect, if any, statistically significant changes. A oneway approach determines any relationship between the factors, and identifies, with a $95 \%$ confidence, if variation in results is statistically significant.

\section{Results and discussion}

\subsection{Microstructural analysis}

Fig. 2 shows the pore size distribution of the LWA and the mortar matrix determined by MIP. Pore structure in both materials is clearly different. In case of LWA, with open porosity of $65 \%$, the average pore size is $0.4 \mu \mathrm{m}$. In case of mortar matrix (measures performed in single matrix samples), most of the pores are smaller than $0.1 \mu \mathrm{m}$, with an average pore size of $0.06 \mu \mathrm{m}$, which means a one order of magnitude difference in comparison to LWA. Open porosity of the mortar matrix is $19 \%$.

Fig. 3 displays the interfacial transition zone (ITZ) between the mortar matrix and both types of aggregates, LWA and CLA. For both types of aggregates, differences in the ITZ are identified between LWA and CLA (Fig. 3c). Porosity in the ITZ shows a considerable reduction as compared to porosity inside the LWA.

Previous studies confirmed the participation in the internal concrete curing of the water inside LWA, which is responsible for the ITZ microstructure [2,30,31], with a higher degree of hydration. Pores of LWA contribute to the total porosity of the sample although they do not participate completely in the fluid transport as they are isolated by the ITZ, which surrounds the aggregate. This is accordance with [31-33], among others. a LWA particle

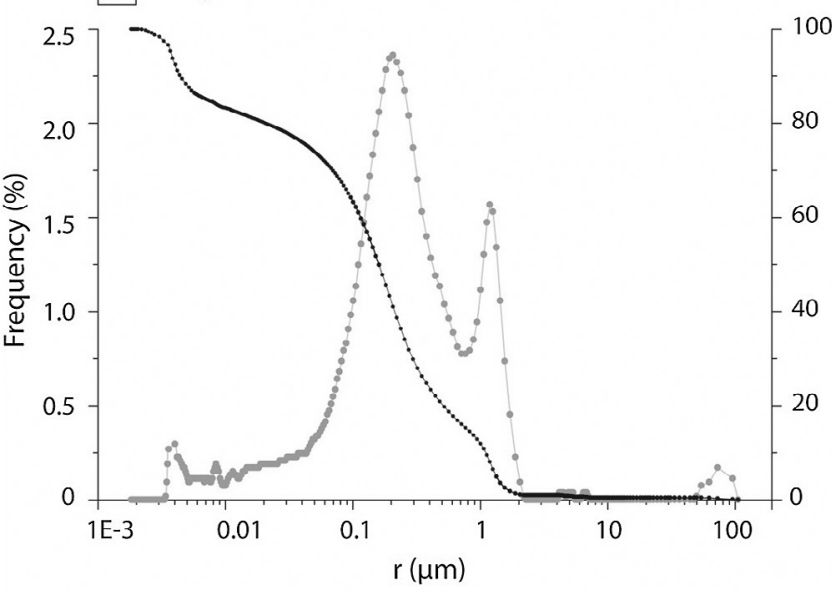

b Mortar matrix

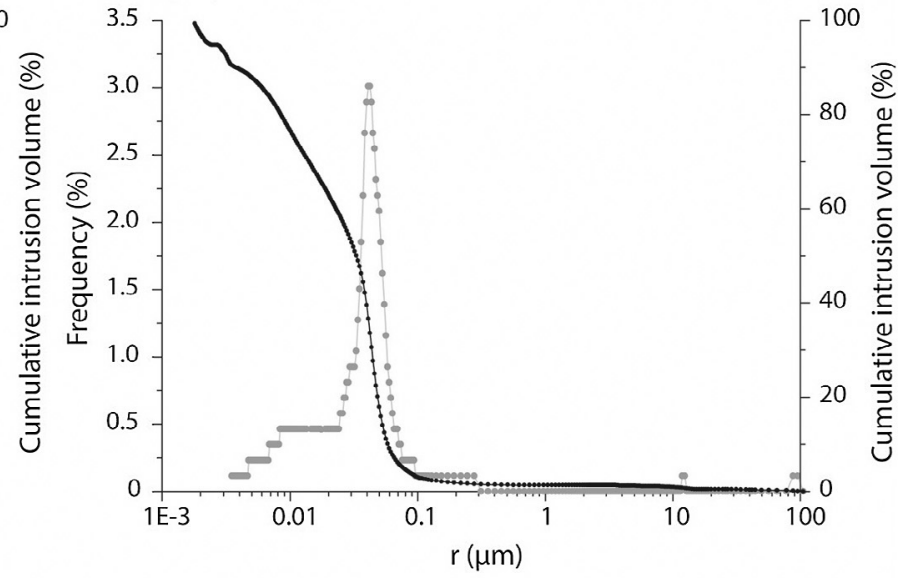

Fig. 2. Cumulative mercury intrusion (black) and pore size distribution (grey) curves of (a) LWA particle and (b) mortar matrix. 

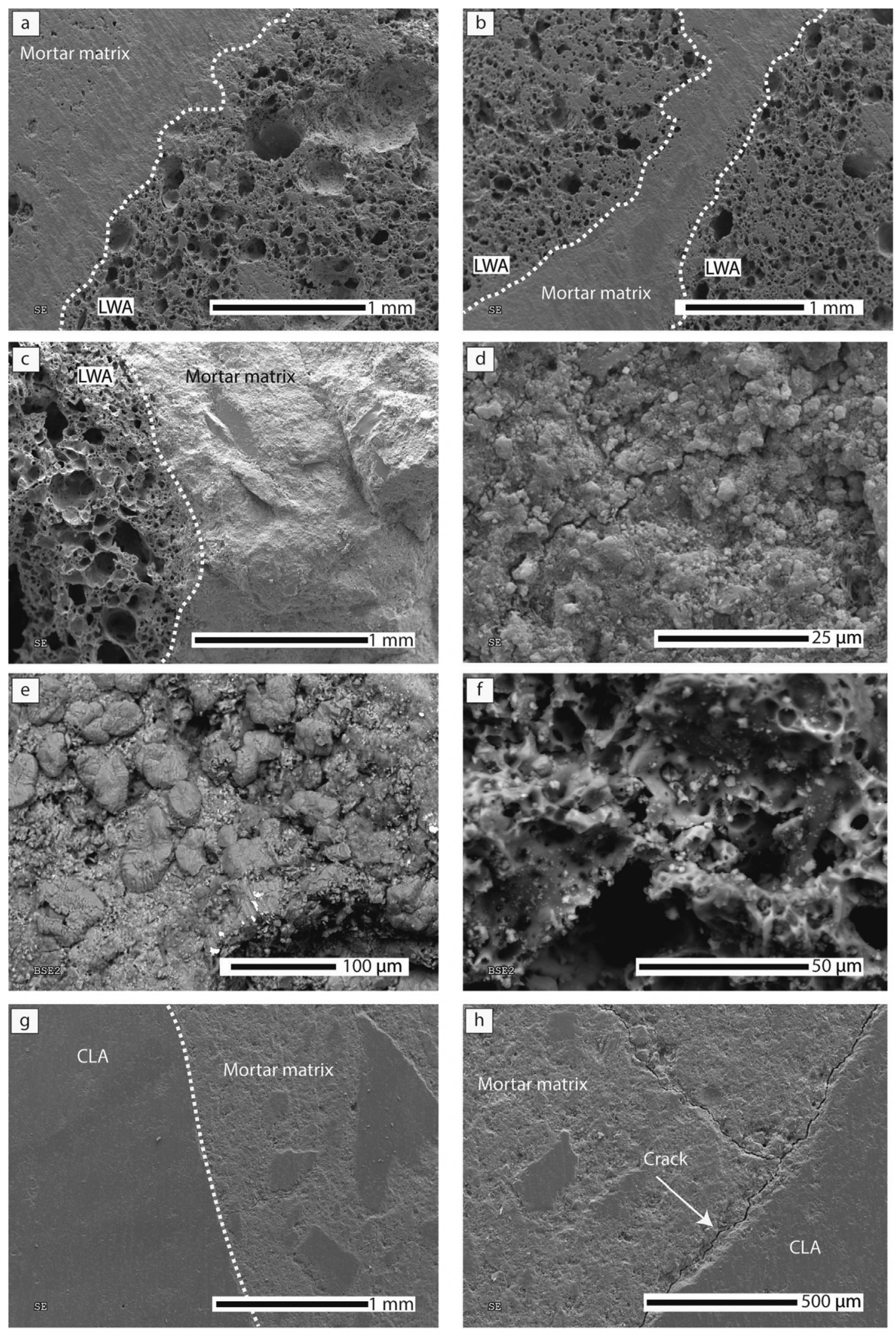

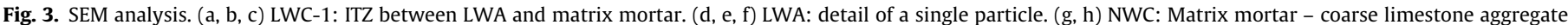
(CLA). Fissures surrounding the limestone particles. 
Inside the LWA, porosity is well distributed with pores easily recognizable (Fig. 3a and b). Nevertheless, near the external part of LWA, a drastic change appears in the pore distribution with the presence of pores with smaller size. Inside LWA, the connectivity between pores is low (Fig. 3a-f) as demonstrated by the isolation between pores. Nevertheless, the presence of microcracks in some LWA particles creates porous channels that favour the rupture and flux of fluids inside the LWA cores (Fig. 3d). These observations were also described by [34].

In case of NWC, single cracks are observed around the coarse limestone aggregates (Fig. $3 \mathrm{~g}$ and $\mathrm{h}$ ). Thus, differences in the ITZ between NWC and LWA are found. In the studied NWC, the presence of microcracks is preferentially placed around the coarse aggregates (CLA), which could create preferential paths to fluid penetration and consequently, could enhance water and gas penetration in the concrete. This observation matches with some studies that indicated the increase of bulk transport properties of mortars with the addition of aggregates. In the studied samples, the cracks usually appear around the coarse aggregates as the aggregate-mortar interface is the weakest zone in the concrete $[35,36]$. They could be related to differences in the modulus of elasticity between the coarse limestone aggregates and the matrix. Differences between modulus of elasticity are significant in the studied NWC, whereas in LWC differences of the modulus of elasticity between LWA particles and matrix are more reduced $[2,32,37]$. Fig. 3a-c and g-h demonstrate that frequency of microcracking in the ITZ between LWA and matrix is lower than in the ITZ between CLA and matrix in the NWC.

Fig. 4 displays the chemical distribution in the ITZ. EDX analysis (Fig. 4a and b) reveals that Ca content across the defined profile (Fig. 4c) decreases substantially from the mortar matrix (with fine $\mathrm{CaCO}_{3}$ aggregates) to the ITZ. Within the LWA particle, Ca concentration fluctuates and the average values remain lower than in the mortar matrix. In the ITZ zone, peaks in Si concentration are predominated by the composition of the outer shell of LWA (Fig. 4b and $\mathrm{c}$ ). The presence of $\mathrm{Si}$ in the outer shell derives from the expanded clay employed in the LWA production. From the outer shell to the inner core of the particle, Si (\%) decreases although it is always higher than in the mortar. $\mathrm{Al}$ and Fe (Fig. 4b and c) present lower concentration than $\mathrm{Ca}$ and $\mathrm{Si}$ with variations that follow a similar pattern to $\mathrm{Si}$, due to the clay influence on the light particles.

Differences in porosity (Fig. 5) are directly related to the LWA incorporation because the $\mathrm{w} / \mathrm{c}$ ratio remains constant for all the samples. Porosity in LWC significantly increases due to the incorporation of porous aggregates, compared to NWC. In the denser samples, the similarity between open and total porosity points to a scarce fraction of closed porosity. Therefore, LWA is not only responsible for an increase in the total porosity of the concrete but also for a significant increase in the closed fraction of the porous network as a consequence of the lower internal connectivity between pores inside the lightweight particles. This fact was also described by [38]. The total porosity slightly decreases from LWC-1 (28\%) to LWC-2 (27\%), whereas in LWC-3 and NWC total porosity drops, respectively, to $17 \%$ and $12 \%$ as LWC content decreases.

\subsection{Mechanical properties}

Compressive and flexural strength ranges from 34 to $46 \mathrm{MPa}$ and from 3.7 to $5.1 \mathrm{MPa}$, respectively (Fig. 6). Mechanical properties for the different samples (both in the compressive and flexural strengths) decrease related to the increase in LWA proportion. In other words, mechanical properties are inversely proportional to total porosity.
The reduction in the mechanical properties is significant between LWC-2 and LWC-3, which is also identified in the results of the dynamic (20.26 GPa-37.65 GPa for LWC-1 to NWC) and static (16.27 GPa-34.40 GPa for LWC-1 to NWC) modulus of elasticity. The dynamically determined elastic modulus (Ed) was slightly higher than the statically determined modulus (Fig. 7). Elastic wave velocities and, consequently, the dynamic elastic modulus are sensitive to the presence of microcracks and pores. However, these discontinuities strongly affect to the static method, performed in loaded conditions and necessary for quantifying the material's deformability. Fig. 7 displays this relationship between static and dynamic modulus through a linear regression. Velocity of P-waves reveals the same pattern in the samples: P-waves velocity decreases in samples with higher LWA content (Fig. 6). As the dynamic elastic modulus was obtained from the propagation velocity and density of the materials (Eq. (2)), Ed presents the same trend and the same relationship with porosity than the described for $V_{P}$. The higher porosity and the lower strength of the lightweight aggregates are directly responsible for the differences in the mechanical properties. The values may present different trends for other types of LWA and cement pastes compositions.

\subsection{Fluid transport in samples}

\subsubsection{Influence of LWA on gas permeability}

In the studied types of concrete, the replacement of CLA by LWA reduces gas permeability. NWC presents the highest air permeability coefficient, although with the greatest dispersion in results (Fig. 8), whereas LWC-1 presents the lowest. However, these variations are weak and the differences are not statistically significant, as we discuss later. Gas permeability coefficients for all the specimens, with compressive strength between 34 and $46 \mathrm{MPa}$, range from $2.2 \times 10^{-16} \pm 5.0 \times 10^{-17} \mathrm{~m}^{2}$ in LWC- 1 to $4.7 \times 10^{-16} \pm 1.7$ $\times 10^{-16} \mathrm{~m}^{2}$ in NWC, which are in accordance to previous studies $[3,5]$. This fact indicates that LWC with high performance in terms of permeability can be produced using LWA [39].

Despite the differences that LWC samples present in total porosity (Fig. 5), all of them have similar gas permeability coefficients. These results indicate that the presence of the aggregates in the concrete matrix contributes to increase their total porosity but does not enhance gas permeability. Thus, a large fraction of LWA is surrounded and encapsulated by a dense layer (Figs. 3 and 4), which partially excludes LWA from the fluid transport. If the mortar matrix has a high quality, i.e., a dense structure with small pores size, the mortar provides protection to the sample.

\subsubsection{Influence of LWA on capillary absorption}

Capillary absorption coefficients show nearly similar results. This fact accentuates the great influence of the mortar matrix in the fluid transport (Fig. 8). Capillary values are in agreement with gas permeability coefficients and confirm that part of the LWA pores do not participate in the fluid transport. The existence of the outer shell surrounding particles of LWA, with closed pores, prevents the access of water to the interior of the particles. However, this shell also contains some open porous through which fluids can move and stablish connection between the LWA and the mortar matrix [33]. After the test, samples were cut in a half to check the water presence in the core sample and water was detected inside some LWA particles, meanwhile others were dry, which corroborates the irregular behaviour of the outer shell.

Water absorption rate through LWA might increase (due to the increase in the pore size) and the suction might decrease, in comparison with the smaller pores of the mortar matrix [40]. The considerable difference between pore size in mortar and LWA (Fig. 2) reduces the capillary action. This fact acts as the limiting factor in the fluid transport. LWA could become full of water accessing to 

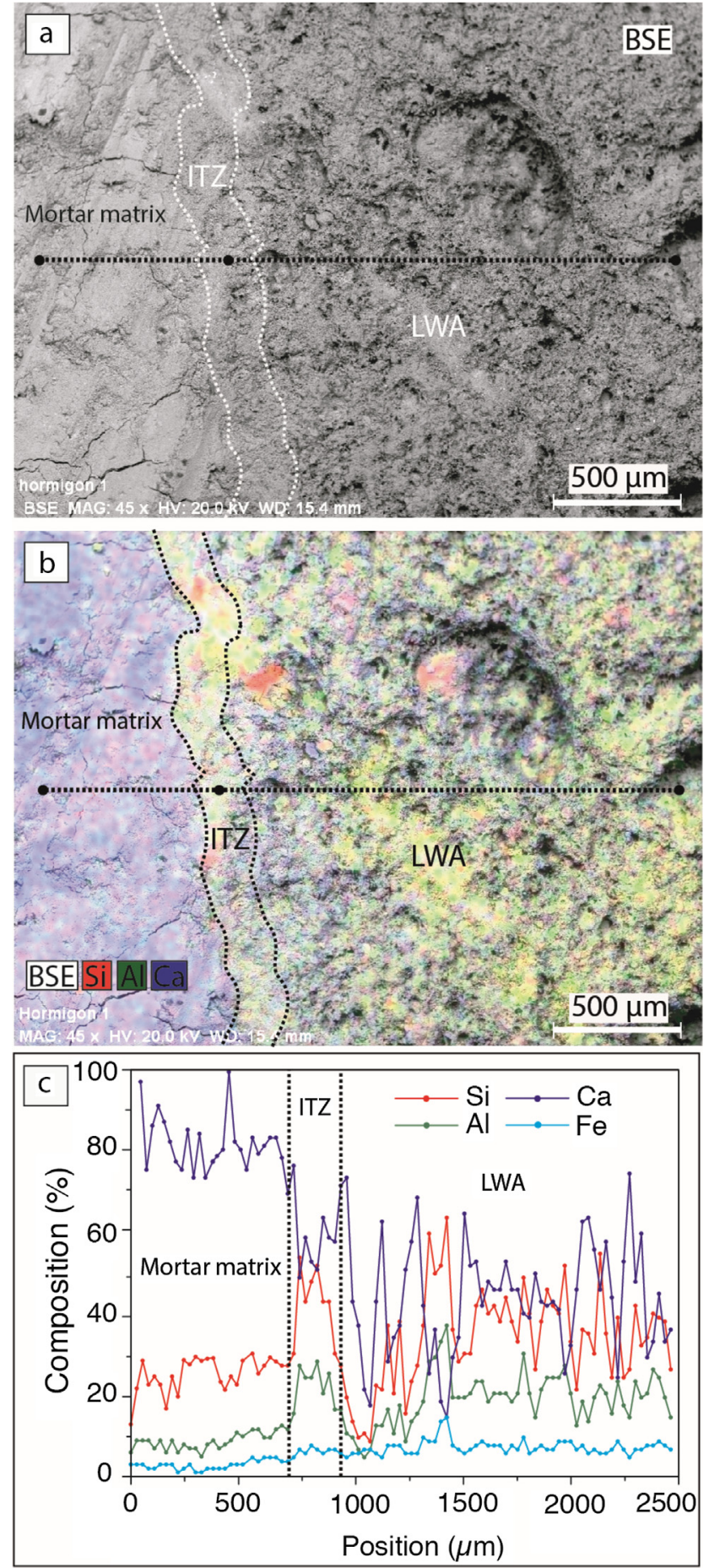

Fig. 4. (a) SEM analysis (BSE image) of a concrete sample differentiating the interfacial transition zone and a single LWA. (b) EDX mapping across the profile mortar matrix - ITZ - LWA. Composition changes are identified with the different colour scales for the analysed elements ( $\mathrm{Si}, \mathrm{Al}, \mathrm{Ca}$ ). (c) Composition changes (\%) for the different studied elements ( $\mathrm{Si}, \mathrm{Al}, \mathrm{Ca}$ and $\mathrm{Fe}$ ) in the marked profile.

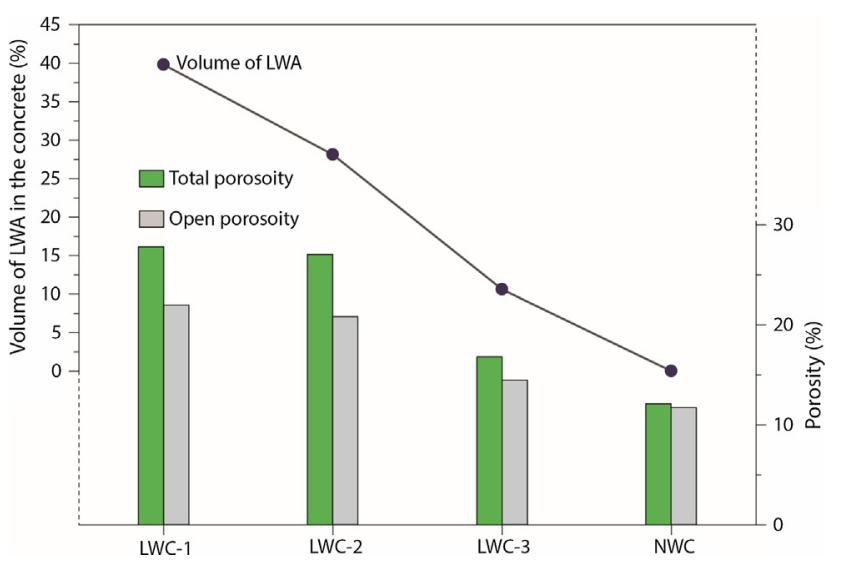

Fig. 5. Volume of LWA (\%), total (\%) and open (\%) porosity in the different samples.

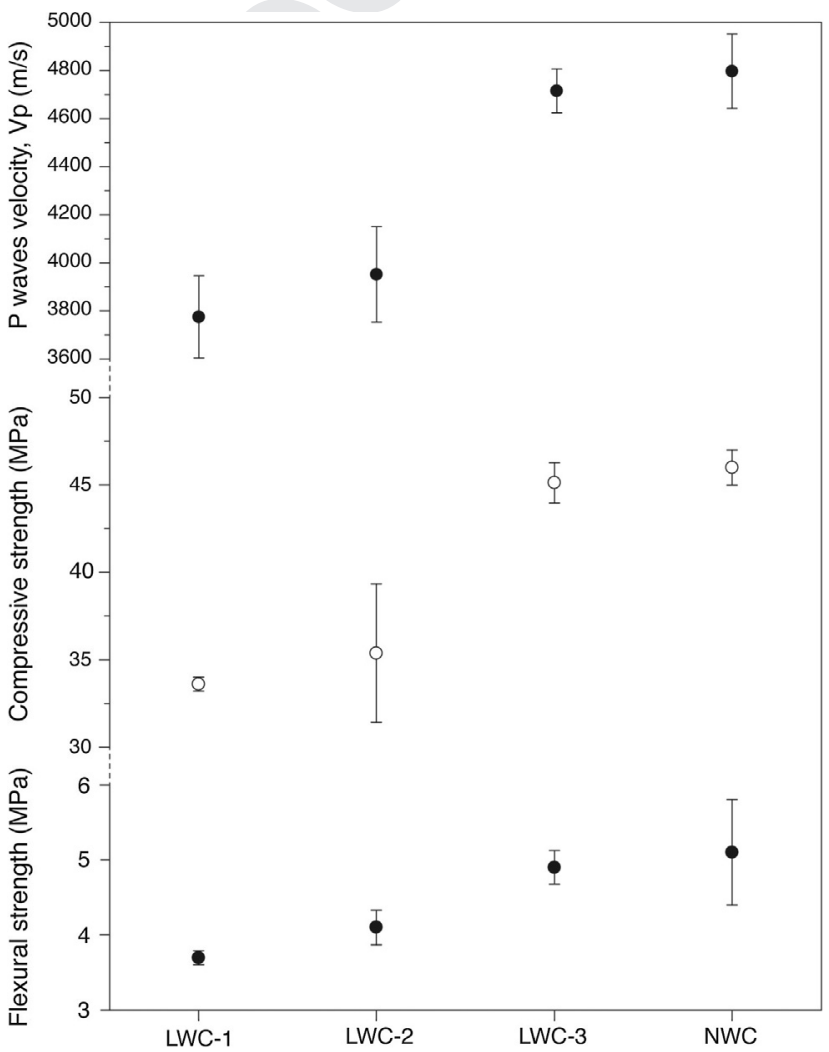

Fig. 6. Compressive and flexural strength and P-waves velocity measured in the different samples.

\subsubsection{Influence of LWA on water retention curves}

Fig. $9 \mathrm{a}$ and $\mathrm{b}$ plot the suction-volumetric water content and the fitted curves according to the van Genuchten model for all types of concrete. Results from the water retention curves coincide with the microstructural characterisation and water absorption capillarity. Thus, as LWA substitutes CLA (i.e., total porosity increases), volumetric water content for a given suction also increases. In both fitted curves (Fig. 9a and b), van Genuchten shape parameter $\alpha$ becomes higher with increasing LWA proportions in the final mixture, especially in the wetting curves. Samples with higher LWA content are capable of retaining more water at higher suctions. This fact may be attributed to the presence of broken lightweight particles in the exposed surface of the tested samples $(\varnothing 50 \mathrm{~mm}$ $\times 5 \mathrm{~mm}$ thick). So that, the volumetric water content is directly 


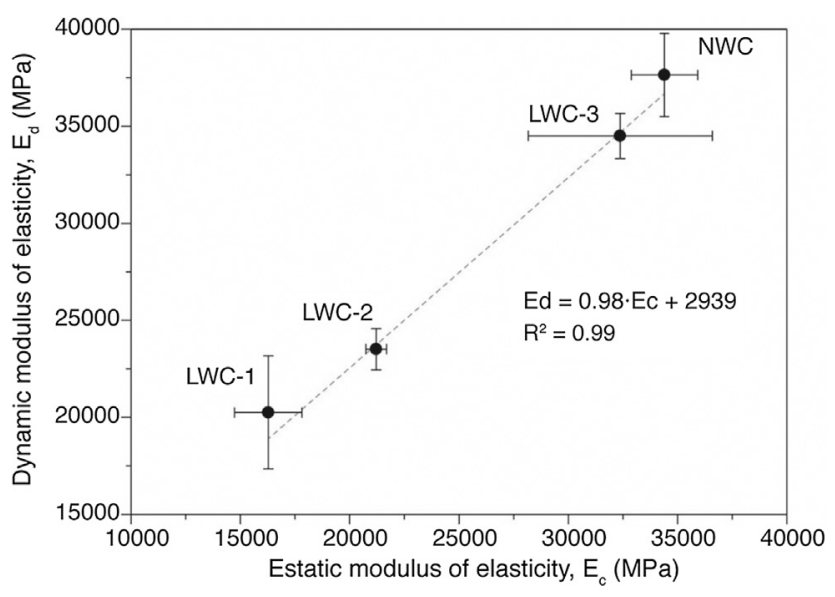

Fig. 7. Relationship between dynamic and static modulus of elasticity.

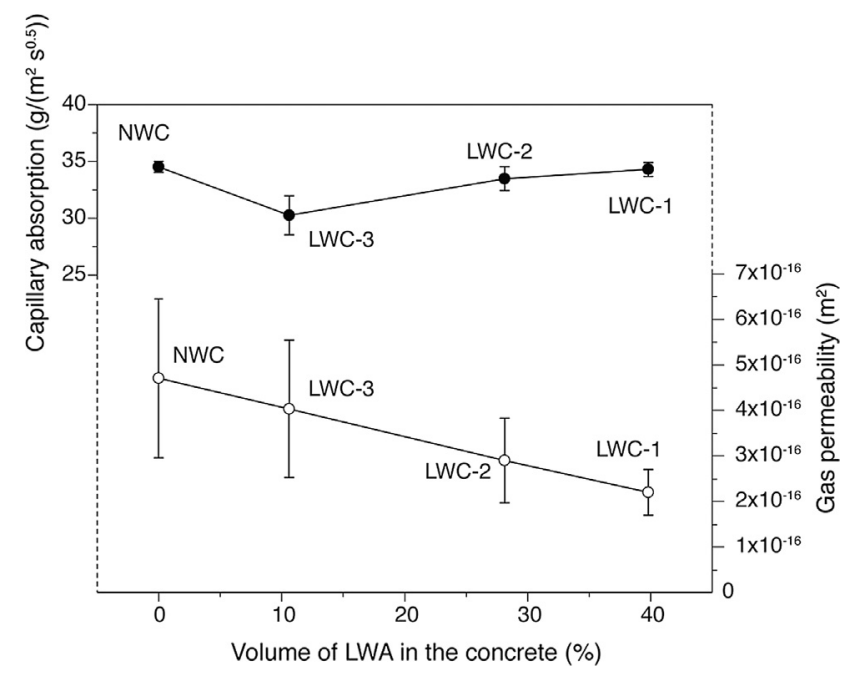

Fig. 8. Capillary absorption and gas permeability coefficients related to the volume (\%) of LWA in the different samples. related to the relative importance of the exposed pores in the LWA surface.

\subsection{ANOVA analysis}

Results from ANOVA (Table 3) indicate significant differences at 95\% confidence when analysing the compressive and flexural strength, the modulus of elasticity and the P-waves velocity. Relative to the compressive and flexural strength, there are two different subsets containing LWC-1 and LWC-2 (subset a) and LWC-3 and NWC (subset b). In other words, LWC-1 and LWC-2 are similar between them and significantly different to LWC-3 and NWC at 95\% confidence. The static modulus of elasticity also shows the same behaviour. P-waves velocity and the dynamic modulus of elasticity establish 4 different subsets with an only type of concrete and, therefore, the different types of concrete can be considered statistically different. Thus, results from ANOVA confirm differences between the lighter concretes, with considerable LWA content and lower mechanical resistance, and the concretes with lower (LWC-3) or no content of LWA (NWC). Even though, the lighter LWC (LWC-1) demonstrates optimal compressive and flexural strength. For instance, reduction of compressive strength is of $26 \%$ comparing LWC- 1 and the most resistant sample (NWC) but total porosity in LWC-1 is $57 \%$ bigger than in NWC, with a similar resistance to the fluids penetration.

Fluid transport is one of the most important factors affecting concrete durability [41]. Values of total porosity indicate that part of the pores of the LWA remain unconnected to the concrete porous system so that coefficients of gaseous permeability and capillary absorption do not increase in the samples with higher values of total porosity. The development of a denser interfacial transition zone between the matrix mortar and the lightweight particles causes a discontinuous path for fluids migration through the concrete porous network. This area shows differences in composition in comparison to both, concrete and LWA core. With the performed tests, it has been proved that lightweight concrete can be produced with low water absorption and gas permeability coefficients. Gas permeability and capillary absorption in the lighter LWC (LWC-1) is lower than those of the NWC, although the coefficients keep at the same order of magnitude. Results from ANOVA do not establish significant differences in the gas permeability coefficient for the different samples, establishing a single subset (subset a; Table 3)

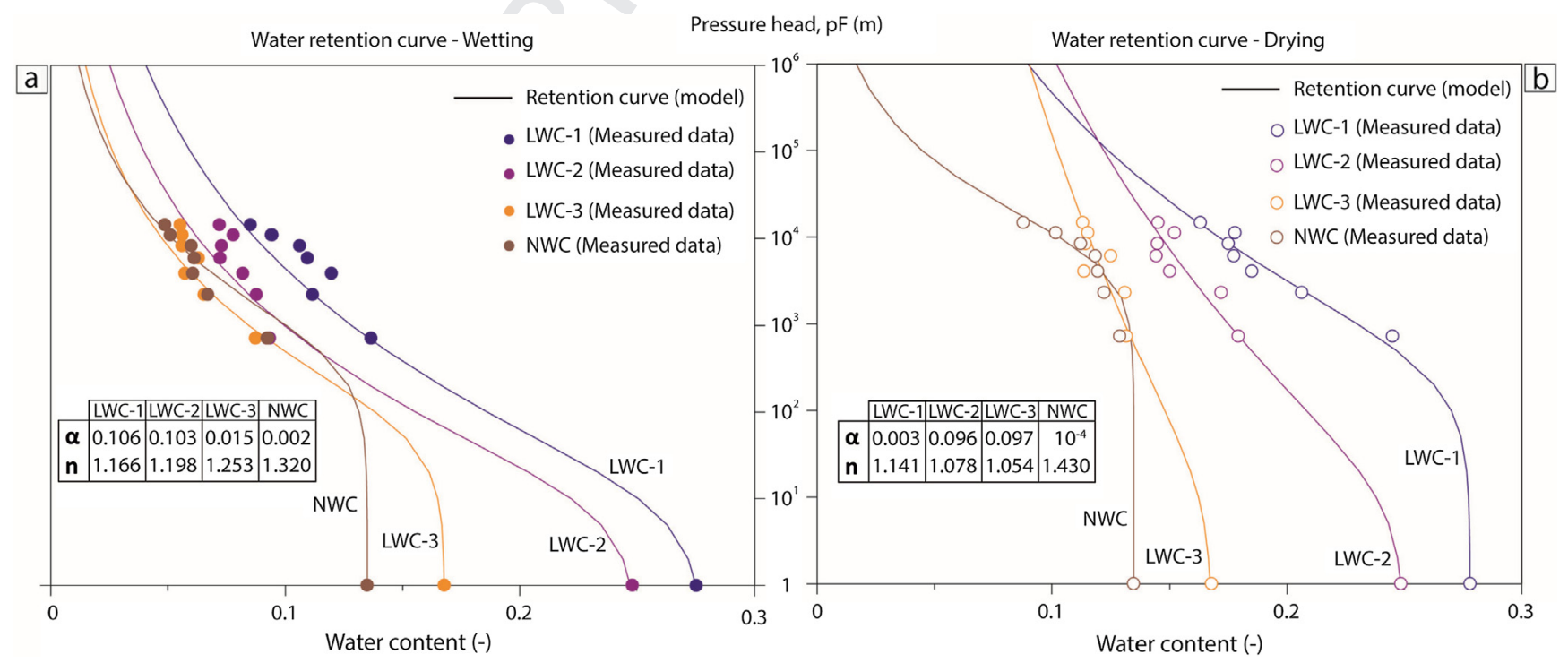

Fig. 9. Water retention curves for the different types of concrete, for both wetting (a) and drying (b) conditions. 
Table 3

ANOVA results for the different variables.

\begin{tabular}{|c|c|c|c|c|c|c|c|}
\hline & $\begin{array}{l}\text { Compressive } \\
\text { strength (MPa) }\end{array}$ & $\begin{array}{l}\text { Flexural strength } \\
(\mathrm{MPa})\end{array}$ & $\begin{array}{l}\text { Dynamic modulus of } \\
\text { elasticity (GPa) }\end{array}$ & $\begin{array}{l}\text { Static modulus of } \\
\text { elasticity (GPa) }\end{array}$ & $\begin{array}{l}\text { P-waves velocity } \\
(\mathrm{m} / \mathrm{s})\end{array}$ & $\begin{array}{l}\text { Gas permeability } \\
\left(\mathrm{m}^{2}\right)\end{array}$ & $\begin{array}{l}\text { Capillary absorption } \\
\left(\mathrm{g} / \mathrm{m}^{2} \mathrm{~s}^{0.5}\right)\end{array}$ \\
\hline LWC-1 & $35.76 \pm 0.21 \mathrm{a}$ & $3.73 \pm 0.09 a$ & $20.26 \pm 1.42 \mathrm{a}$ & $16.27 \pm 1.54 \mathrm{a}$ & $3892 \pm 157 a$ & $2.20 \times 10^{-1}$ & $34.30 \pm 0.61 \mathrm{a}$ \\
\hline LWC-2 & $38.42 \pm 2.40 \mathrm{a}$ & $4.08 \pm 0.23 a$ & $23.51 \pm 2.70 \mathrm{~b}$ & $21.21 \pm 0.48 a$ & $4210 \pm 362 b$ & $2.90 \times 10^{-16} \pm 9.23 \times 10^{-17} \mathrm{a}$ & $33.48 \pm 1.01 \mathrm{a}$ \\
\hline LWC-3 & $45.62 \pm 0.39 b$ & $5.94 \pm 0.23 b$ & $34.50 \pm 0.50 c$ & $32.38 \pm 4.21 b$ & $4753 \pm 265 c$ & $4.03 \times 10^{-16} \pm 1.50 \times 10^{-16} \mathrm{a}$ & $30.26 \pm 1.71 b$ \\
\hline NWC & $45.59 \pm 0.97 b$ & $5.09 \pm 0.70 b$ & $37.65 \pm 2.01 \mathrm{~d}$ & $34.40 \pm 1.52 b$ & $4210 \pm 251 d$ & $4.71 \times 10^{-16} \pm 1.71 \times 10^{-16} \mathrm{a}$ & $34.53 \pm 0.48 a$ \\
\hline
\end{tabular}

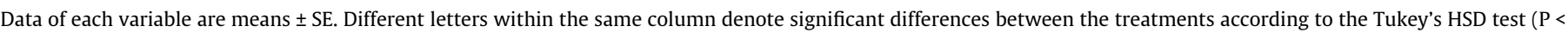
$5 \%$ ). Identical letters within the same column denote no significant differences ( $P>5 \%$ ).

in which all samples were included. However, for the capillary absorption, LWC-3 demonstrates differences compared with the other three samples (LWC-1, LWC-2 and NCW) probably as a consequence of the high variation in results from LWC-3 (Fig. 9). The fluid transport tests confirm, supported by both, SEM and ANOVA analysis, that the quality of the mortar matrix is the most important parameter that controls the fluid transport in the studied concretes. LWA have higher absorption capacity and permeability than the surrounding matrix but the fluid transport in the samples is closely related to the accessible porosity of the concrete matrix, responsible for the improvement of the sample fluid resistance. The influence of LWA in the transport properties depends on the type of transport mechanism. In this case, the role of LWA in permeability and capillary absorption is different and confirm the trends presented in previous studies. To better consider these effects, future work should be developed with concrete containing different types of LWA.

\section{Conclusions}

The present study evaluates the effect of lightweight aggregate content in the mechanical behaviour and fluid transport on several types of concrete. Differences in open porosity between LWA (65\%) and the mortar (19\%) are noticeable. LWA porosity is well distributed and presents larger pore size.

The interfacial transition zone (ITZ) provides a high-quality aggregate-matrix interface. Pores of LWA contribute to the sample total porosity but do not totally participate in the fluid transport through the concrete as they are isolated by an external outer shell. Microstructural changes between the mortar, the ITZ and the LWA core are also reflected in the evolution of the chemical composition in the interfacial transition zone. Based on the experimental results and discussion, we concluded that:

1. Mechanical properties for the different samples are affected by LWA presence and decrease as total porosity increases. Compressive and flexural strengths, dynamic and static modulus of elasticity and P-waves velocity reveal the same pattern in the different types of concrete.

2. Gas permeability slightly decreases with the presence of LWA in the samples. In addition, NWC, entirely composed by coarse limestone aggregates, presents the highest air permeability coefficient. Cracks occur around CLA because of the differences in the modulus of elasticity and enhance water and gas penetration in NWC samples.

3. Capillary absorption remains nearly constant for all the concrete types. This fact confirms the role of the LWA outer shell as a preventive barrier, which hampers the access of water to their interior. Although this outer shell has some open porosity, the considerable pore size differences between the mortar and LWA reduce the capillary action and hinder the continuity in the fluid transport.

4. When LWA particles are cut in a half, the volumetric water content, accumulated in the exposed interior pore surface, increases in LWC compared to NWC.
5. ANOVA analysis establishes significant differences in the mechanical properties between the different types of concrete. However, ANOVA does not establish significant differences in the fluid transport coefficients.

6. Results highlight the great influence of the mortar matrix on concrete quality. It controls the fluid transport through the cementitious material and, consequently, its durability.

\section{Acknowledgements}

This research was partially funded by the University of Alicante through the projects GRE13-03, GRE15-19 and VIGROB-256. The authors thank to J. Miralles for his inestimable technical support.

\section{Conflicts of interest}

None.

\section{References}

[1] V. Ducman, B. Mirtic, Water vapour permeability of lightweight concrete prepared with different types of lightweight aggregates, Constr. Build. Mater. 68 (2014) 314-319.

[2] J.A. Bogas, M.G. Gomes, S. Real, Capillary absorption of structural lightweight aggregate concrete, Mater. Struct. 48 (2015) 2869-2883.

[3] M. Geiker, H. Grube, T. Luping, L.O. Nilsson, C. Andrade, Laboratory test methods, in: J. Kropp, H.K. Hilsdorf (Eds.), Rilem Report 12 - Performance Criteria for Concrete Durability: State of the Art Report by Rilem Technical Committee TC 116-PCD. Performance of Concrete as a Criterion of its Durability. Spon, London, 1995, pp. 213-257.

[4] A.M. Neville, Properties of concrete, 1995.

[5] S. Real, J.A. Bogas, Oxygen permeability of structural lightweight aggregate concrete, Constr. Build. Mater. 137 (2017) 21-34.

[6] R. Henkensiefken, J. Castro, D. Bentz, T. Nantung, J. Weiss, Water absorption in internally cured mortar made with water-filled lightweight aggregate, Cem. Concr. Res. 39 (2009) 883-892.

[7] N.U. Kockal, T. Ozturan, Durability of lightweight concretes with lightweight fly ash aggregates, Constr. Build. Mater. 25 (2011) 1430-1438.

[8] R. Wasserman, A. Bentur, Interfacial interactions in lightweight aggregate concretes and their influence on the concrete strength, Cem. Concr. Compos. 18 (1996) 67-76.

[9] T.Y. Lo, H.Z. Cui, W.C. Tang, W.M. Leung, The effect of aggregate absorption on pore area at interfacial zone of lightweight concrete, Constr. Build. Mater. 22 (2008) 623-628.

[10] T.Y. Lo, W.C. Tang, H.Z. Cui, The effects of aggregate properties on lightweight concrete, Build. Environ. 42 (2007) 3025-3029.

[11] T.Y. Lo, H.Z. Cui, W.C.P. Tang, Phase constitution at interfacial between lightweight aggregate/concrete cement paste composite, Mater. Res. Innovations 12 (2008) 123-126.

[12] V.M. Sanchez-Fajardo, M.E. Torres, A.J. Moreno, Study of the pore structure of the lightweight concrete block with lapilli as an aggregate to predict the liquid permeability by dielectric spectroscopy, Constr. Build. Mater. 53 (2014) 225234.

[13] UNE-EN 933-1, Tests for geometrical properties of aggregates - Part 1: Determination of particle size distribution - Sieving method, 2012.

[14] UNE-EN 1097-3, Tests for mechanical and physical properties of aggregates Part 3: Determination of loose bulk density and voids, 1999.

[15] UNE-EN 1097-6, Tests for mechanical and physical properties of aggregates Part 6: Determination of particle density and water absorption, 2014.

[16] UNE-EN 933-5, Test for geometrical properties of aggregates - Part 5: Determination of percentage of crushed and broken surfaces in coarse aggregate particles, 1999 . 
[17] A. Fernandez-Fanjul, A. Tenza-Abril, Méthode Fanjul: Dosage pondéral des bétons légers et lourds, Annales Du Bâtiment Et Des Travaux Publics 5 (2012) $32-50$.

[18] UNE-EN 1936, Natural stone test methods - Determination of real density and apparent density, and of total and open porosity, 2007.

[19] UNE-EN 12390-3, Testing hardened concrete - Part 3: Compressive strength of test specimens, 2009.

[20] UNE-EN 12390-5, Testing hardened concrete - Part 5: Flexural strength of test specimens, 2009 .

[21] UNE-EN 12390-13, Testing hardened concrete - Part 13: Determination of secant modulus of elasticity in compression, 2014.

[22] UNE 83966, Concrete durability. Test methods. Conditioning of concrete test pieces for the purpose of gas permeability and capilar suction tests, 2008.

[23] T.C. Rilem, 116-PCD, permeability of concrete as a criterion of its durability, Mater. Struct. 32 (1999) 174-179.

[24] UNE 83982, Concrete durability. Test methods. Determination of the capillar suction in hardened concrete. Fagerlund method, 2008.

[25] D. Benavente, C. Pla, N. Cueto, S. Galvañ, J. Martínez-Martínez, M.A. García-delCura, S. Ordóñez, Response to ENGE07253 Discussion of: "Predicting water permeability in sedimentary rocks from capillary imbibition and pore structure" by D. Benavente et al., Eng. Geol. (2015) [doi: 10.1016/j. enggeo.2015.06.003], Eng. Geol. 204 (2016) 123-125.

[26] D. Benavente, J.C. Cañaveras, S. Cuezva, L. Laiz, S. Sanchez-Moral, Experimental definition of microclimatic conditions based on water transfer and porous media properties for the conservation of prehistoric constructions: Cueva Pintada at Galdar, Gran Canaria, Spain, Environ. Geol. 56 (2009) 1495-1504.

[27] S. Schneider, D. Mallants, D. Jacques, Determining hydraulic properties of concrete and mortar by inverse modelling, Mater. Res. Soc. Symp. Proc. 1475 (2012).

[28] K. Beck, M. Al-Mukhtar, O. Rozenbaum, M. Rautureau, Characterization, water transfer properties and deterioration in tuffeau: building material in the Loire valley - France, Build. Environ. 38 (2003) 1151-1162.

[29] M.T. Van Genuchten, A closed-form equation for predicting the hydraulic conductivity of unsaturated soils, Soil Sci. Soc. Am. J. 44 (1980) 892-898.
[30] A. Elsharief, M.D. Cohen, J. Olek, Influence of lightweight aggregate on the microstructure and durability of mortar, Cem. Concr. Res. 35 (2005) 13681376.

[31] X.M. Liu, K.S. Chia, M.H. Zhang, Water absorption, permeability, and resistance to chloride-ion penetration of lightweight aggregate concrete, Constr. Build. Mater. 25 (2011) 335-343.

[32] K.S. Chia, M.H. Zhang, Water permeability and chloride penetrability of highstrength lightweight aggregate concrete, Cem. Concr. Res. 32 (2002) 639-645.

[33] P. Spiesz, Q.L. Yu, H.J.H. Brouwers, Development of cement-based lightweight composites - Part 2: durability-related properties, Cem. Concr. Compos. 44 (2013) $30-40$.

[34] J.A. Bogas, A. Gomes, M.G. Gomes, Estimation of water absorbed by expanding clay aggregates during structural lightweight concrete production, Mater. Struct. 45 (2012) 1565-1576.

[35] J.M.F. Calixto, Microcracking of high performance concrete subjected to biaxial tension - compression stresses, Mater. Res. 5 (2002) 295-299.

[36] H.S. Wong, M. Zobel, N.R. Buenfeld, R.W. Zimmerman, Influence of the interfacial transition zone and microcracking on the diffusivity, permeability and sorptivity of cement-based materials after drying, Mag. Concr. Res. 61 (2009) 571-589.

[37] X.M. Liu, K.S. Chia, M.H. Zhang, Development of lightweight concrete with high resistance to water and chloride-ion penetration, Cem. Concr. Compos. 32 (2010) 757-766.

[38] J.A. Bogas, A. Mauricio, M.F.C. Pereira, Microstructural analysis of iberian expanded clay aggregates, Microsc. Microanal. 18 (2012) 1190-1208.

[39] E. Guneyisi, M. Gesoglu, O. Pursunlu, K. Mermerdas, Durability aspect of concretes composed of cold bonded and sintered fly ash lightweight aggregates, Compos. B Eng. 53 (2013) 258-266.

[40] D. Benavente, C. Pla, N. Cueto, S. Galvañ, J. Martínez-Martínez, M.A. García-delCura, S. Ordóñez, Predicting water permeability in sedimentary rocks from capillary imbibition and pore structure, Eng. Geol. 195 (2015) 301-311.

[41] L. Zong, Z. Fei, S. Zhang, Permeability of recycled aggregate concrete containing fly ash and clay brick waste, J. Cleaner Prod. 70 (2014) 175-182. 